\title{
Temperature Control via Affine Nonlinear Systems for Intermediate Point of Supercritical Once-Through Boiler Units
}

\author{
Hong Zhou, Changkun Liu, Zhi-Wei Liu, and Wenshan Hu \\ School of Power and Mechanical Engineering, Department of Automation, Wuhan University, Wuhan 430072, China \\ Correspondence should be addressed to Wenshan Hu; wenshan.hu@whu.edu.cn
}

Received 10 April 2014; Revised 21 June 2014; Accepted 21 June 2014; Published 22 July 2014

Academic Editor: Chengjin Zhang

Copyright ( 2014 Hong Zhou et al. This is an open access article distributed under the Creative Commons Attribution License, which permits unrestricted use, distribution, and reproduction in any medium, provided the original work is properly cited.

\begin{abstract}
For the operation of the supercritical once-through boiler generation units, the control of the temperature at intermediate point (IPT) is highly significant. IPT is the steam temperature at the outlet of the separator. Currently, PID control algorithms are widely adopted for the IPT control. However, PID cannot achieve the optimal performances as the units' dynamic characteristic changes at different working points due to the severe nonlinearity. To address the problem, a new control algorithm using affine nonlinear system is adopted for a $600 \mathrm{MW}$ unit in this paper. In order to establish the model of IPT via affine nonlinear system, the simplified mechanism equations on the evaporation zone and steam separator of the unit are established. Then, the feedback linearizing control law can be obtained. Full range simulations with the load varying from $100 \%$ to $30 \%$ are conducted. To verify the effectiveness of the proposed control algorithm, the performance of the new method is compared with the results of the PID control. The feed-water flow disturbances are considered in simulations of both of the two control methods. The comparison shows the new method has a better performance with a quicker response time and a smaller overshoot, which demonstrates the potential improvement for the supercritical once-through boiler generation unit control.
\end{abstract}

\section{Introduction}

Developing supercritical once-through boiler generation units [1] is of great importance due to the threats of global warming and severe air pollution. The supercritical units have the advantage of high power generation efficiency up to $45 \%$. Moreover, they are able to maintain relatively high efficiency even at low loads. However, as the side effects, the system is severely nonlinear, which is difficult to control.

On the one hand, high performance is required for the IPT control, as $1^{\circ} \mathrm{C}$ variation of IPT could end up with fluctuations of main-steam temperature around $8^{\circ} \mathrm{C}$ generally. The variation of main-steam temperature has profound effects on the stability, security, and efficiency of supercritical units. Therefore, the IPT control is a key problem to all of the units. On the other hand, more and more distributed energy is integrated into the grid. Renewable energy such as solar and wind power has bad capacity of peak regulation which leads to the increasing requirement of load regulation for the traditional units. To improve the control performance, the nonlinearity must be addressed.
For nonlinear systems [2], researchers have developed many control strategies for the IPT control, such as adaptive control [3, 4], fuzzy control [5-7], neural network control [810], predictive control [11-13], and coordinated control [14].

In 2000, Åström and Bell established a simplified nonlinear model of the drum-boiler unit [15]. The model has been widely used; however, the unbalance between feedwater flow and coal combustion [16] could cause disturbance on steam temperature, and the model cannot be used in the situations of once-through boilers. Fuzzy controller was applied to once-through boiler [17] in 2006, and adaptive control strategy was came up with in 2007 [18] which had good effect on slowly changing system. However, it was not able to deal with the situations of sudden load change.

In [19], a fuzzy autoregressive moving average model was proposed and applications of online self-organizing fuzzy logic controller were presented to a boiler-turbine system in a power plant. However, the techniques have been applied for nonmodel-based controller design and the control rules may not be accurate enough as the plant model information is not utilized. The applications of dynamic matrix control 
(DMC) to a drum-type boiler-turbine system were presented in [20], but the validation of the step-response model may be unsatisfied in designing the DMC. Sode-Yome et al. proposed some methods which can be used in stability control of power system [21], and the controller was designed for ultrasupercritical once-through boiler power plant [22]. This type of power plant could be used mainly for base line power generation and this technique may not be suitable for the power plants with frequent load changes.

With rapid development of nonlinear control theory and affine nonlinear system [23-26], currently exact linearization theory [27] has been applied into numerous industrial applications such as nonlinear automatic control of helicopter [28] and power system [29].

In this paper, affine nonlinear system based on exact feedback linearization [30-32] is adopted on the control of IPT for supercritical units. The contents of the paper are outlined as follows. In Section 2, by establishing the model of the evaporation zone and steam separator, the appropriate model via affine nonlinear system is chosen and the exact feedback linearizing control rules are obtained. The stability analysis of the chosen nonlinear system is made and simulations on the PIT control via affine nonlinear system are conducted in Section 3. In Section 4, to verify the new method proposed in the paper, the control performances of the nonlinear optimal control and PID control are compared with the load varying from $100 \%$ to $30 \%$. The results show the new control method is more effective comparing with the conventional PID as the conclusion is made in Section 5.

\section{Modeling and Controller Design via Affine Nonlinear Systems}

2.1. Model of the Evaporation Zone and Steam-Separator. In order to simplify boiler model [33], the following hypothesis is given. (1) The unit is divided into the evaporation zone, steam separator, overheated zone, steam pipeline, and turbine. (2) No heat conductions and exchanges exist along the pipe, and the steam has heat-absorbing uniformity. (3) The same heat pipes with the uniform diameter and thickness are used. (4) The radial intensity of heat transferring around the pipe is uniform. (5) The steam in the pipe flows with a constant speed along the pipe. Here is a list of all physical parameters used in this paper:

$H_{\text {sm }}$ : medium enthalpy at the outlet of the economizer $(\mathrm{kJ} / \mathrm{kg})$;

$P_{s m}$ : steam pressure at the outlet of the economizer (MPa);

$D_{s m}$ : feed-water flow at the outlet of the economizer $(\mathrm{kg} / \mathrm{s})$;

$P_{z f}$ : steam pressure at the outlet of the evaporation zone $(\mathrm{MPa})$;

$T_{z f}$ : steam temperature at the outlet of the evaporation zone $(\mathrm{K})$;

$\rho_{z f}$ : steam density at the outlet of the evaporation zone $\left(\mathrm{kg} / \mathrm{m}^{3}\right)$;

$M_{z f j}$ : metal mass of the evaporation zone $(\mathrm{kg})$;
$D_{z f}$ : steam flow at the outlet of the evaporation zone $(\mathrm{kg} / \mathrm{s})$;

$U_{z f}$ : internal energy of steam at the outlet of the evaporation zone $(\mathrm{kJ} / \mathrm{kg})$;

$T_{z f j}$ : metal temperature at the outlet of the evaporation zone $(\mathrm{K})$;

$C_{z f j}$ : specific heat capacity of the metal in evaporation zone $(\mathrm{kJ} /(\mathrm{kg} \cdot \mathrm{K}))$;

$H_{z f}$ : steam enthalpy at the outlet of the evaporation zone $(\mathrm{kJ} / \mathrm{kg})$;

$\sigma_{z f}$ : average steam density in evaporation zone $\left(\mathrm{kg} / \mathrm{m}^{3}\right)$;

$Q_{z f}$ : heat which the steam transfers to the metal pipe in evaporation zone $(\mathrm{kJ} / \mathrm{s})$;

$Q_{z f f}$ : heat which the metal pipe transfers to the steam in evaporation zone $(\mathrm{kJ} / \mathrm{s})$;

$L, V_{z f}$ : length (m) and volume $\left(\mathrm{m}^{3}\right)$ of the evaporation zone;

$M_{f l j}:$ metal mess of the steam separator $(\mathrm{kg})$;

$A$ : inner surface area of the steam separator $\left(\mathrm{m}^{2}\right)$;

$T_{f l}$ : steam temperature at the outlet of the separator $(\mathrm{K})$;

$V_{f l}$ : volume of the separator $\left(\mathrm{m}^{3}\right)$;

$T_{f l j}:$ metal temperature at the outlet of the separator $(\mathrm{K})$;

$D_{f l}$ : steam flow at the outlet of the separator $(\mathrm{kg} / \mathrm{s})$;

$\rho_{f l}$ : steam density at the outlet of the separator $\left(\mathrm{kg} / \mathrm{m}^{3}\right)$;

$C_{f l j}$ : specific heat capacity of the separator's metal $(\mathrm{kJ} /(\mathrm{kg} \cdot \mathrm{K}))$;

$H_{f l}$ : steam enthalpy at the outlet of the separator $(\mathrm{kJ} / \mathrm{kg})$;

$P_{f l}$ : steam pressure at the outlet of the separator $(\mathrm{MPa})$;

$Q_{f l}$ : heat which the steam transfers to the metal pipe in separator $(\mathrm{kJ} / \mathrm{s})$;

$C_{p}$ : specific heat capacity under constant pressure in pipe (constant);

$V_{c}$ : average specific heat capacity of the steam in heattransfer zone $(\mathrm{kJ} /(\mathrm{kg} \cdot \mathrm{K}))$;

$B$ : coal-fired value $(\mathrm{kg} / \mathrm{s})$;

$\Delta T:$ the steam temperature difference between input and output of the economizer $(\mathrm{K})$.

By establishing the differential equations for the supercritical once-through boiler generation units, the model of the evaporation zone and the steam-separator can be acquired $[34,35]$. 
2.1.1. Modeling of the Steam Separator. If there is no other source which transfers heat to the separator, the following equations can be written as

$$
\begin{gathered}
D_{z f}-D_{f l}=\frac{V_{f l} d \rho_{f l}}{d \tau}, \\
D_{z f} H_{z f}-D_{f l} H_{f l}=\frac{V_{f l} d\left(\rho_{f l} H_{f l}\right)}{d \tau}+Q_{f l}, \\
Q_{f l}=\alpha A\left(T_{f l}-T_{f l j}\right), \\
Q_{f l}=\frac{M_{f l j} C_{f l j} d T_{f l j}}{d \tau} .
\end{gathered}
$$

As $d H_{f l} / d T_{f l}=C_{p}$, the equation is simplified as

$$
\begin{aligned}
\frac{d H_{f l}}{d \tau}= & \frac{D_{z f}\left(H_{z f}-H_{f l}\right)}{V_{f l} \rho_{f l}}-\frac{Q_{f l}}{V_{f l} \rho_{f l}}, \\
\frac{d Q_{f l}}{d \tau}= & \frac{\alpha A}{C_{p} V_{f l} \rho_{f l}} D_{z f}\left(H_{z f}-H_{f l}\right) \\
& -\left(\frac{\alpha A}{C_{p} V_{f l} \rho_{f l}}+\frac{\alpha A}{M_{f l j} c_{f l j}}\right) Q_{f l} .
\end{aligned}
$$

2.1.2. Modeling of the Evaporation Zone. It is assumed that the steam and the liquid medium are thoroughly mixed without any pressure loss. Therefore, the differential equations are presented as

$$
\begin{gathered}
D_{s m}-D_{z f}=V_{z f} \frac{d \rho_{z f}}{d \tau} \\
Q_{z f f}+D_{s m} H_{s m}-D_{z f} H_{z f}=V_{z f} \frac{d\left(\rho_{z f} U_{z f}\right)}{d \tau}, \\
Q_{z f f}=K D_{z f}^{n}\left(T_{z f j}-T_{z f}\right), \\
Q_{z f}-Q_{z f f}=M_{z f j} c_{z f j} \frac{d T_{z f j}}{d \tau} .
\end{gathered}
$$

Due to $U_{z f}=H_{z f}-\left(P_{z f} / \rho_{z f}\right)$, the result is simplified as

$$
V_{z f} \frac{d\left(H_{z f} \rho_{z f}\right)}{d \tau}=V_{z f} \frac{d P_{z f}}{d \tau}+Q_{z f f}+D_{s m} H_{s m}-D_{z f} H_{z f} .
$$

As $Q_{z f}-Q_{z f f}=\varphi B V_{c} \Delta T$, the equation can be further simplified as

$$
\frac{d Q_{z f f}}{d \tau}=\frac{K D_{z f}^{n} \varphi B V_{c} \Delta T}{M_{z f j} c_{z f j}}-\frac{K D_{z f}^{n}}{C_{p}} \frac{d H_{z f}}{d \tau},
$$

where $d H_{z f} / d T_{z f}=C_{p}, K D_{z f}^{n}$ is considerd as a constant.

Meanwhile, the steam evaporated equation is given as

$$
D_{s m}-D_{z f}=V_{z f} \frac{d \rho_{z f}}{d \tau}=V_{z f} \frac{\partial \sigma_{z f}}{\partial P_{z f}} \frac{d P_{z f}}{d \tau}=V_{z f} \mu_{z f} \frac{d P_{z f}}{d \tau} .
$$

The steam momentum equation is

$$
P_{z f}-P_{s m}=\frac{L \varepsilon D_{z f}^{2}}{\rho_{z f}}
$$

The derivative of (7) is

$$
\frac{d D_{z f}}{d \tau}=-\frac{\rho_{z f}^{2}+\mu_{z f} L \varepsilon D_{z f}^{2}}{2 \rho_{z f} V_{z f} \mu_{z f} L \varepsilon}+\frac{\rho_{z f}^{2}+\mu_{z f} L \varepsilon D_{z f}^{2}}{2 V_{z f} \mu_{z f} D_{z f} L \varepsilon \rho_{z f}} D_{s m} .
$$

Therefore, the system's state equation is obtained as

$$
\begin{gathered}
\frac{d H_{f l}}{d \tau}=\frac{D_{z f}\left(H_{z f}-H_{f l}\right)}{V_{f l} \rho_{f l}}-\frac{Q_{f l}}{V_{f l} \rho_{f l}}, \\
\frac{d Q_{f l}}{d \tau}=\frac{\alpha A}{C_{p} V_{f l} \rho_{f l}} D_{z f}\left(H_{z f}-H_{f l}\right) \\
\frac{-\left(\frac{\alpha A}{C_{p} V_{f l} \rho_{f l}}+\frac{\alpha A}{M_{f l j} c_{f l j}}\right) Q_{f l},}{d \tau}=\frac{1}{V_{z f} \rho_{z f}}\left(Q_{z f f}-\frac{D_{z f}}{\mu_{z f}}\right) \\
\frac{d Q_{z f f}}{d \tau}=-\left(\frac{1}{\mu_{z f}}+H_{s m}-H_{z f}\right) \frac{D_{s m}}{V_{z f} \rho_{z f}}, \\
\left.\frac{D_{z f}-\mu_{z f} Q_{z f f}}{C_{p} V_{z f} \rho_{z f} \mu_{z f}}\right) K D_{z f}^{n}+\frac{K D_{z f}^{n} \varphi B V_{c} \Delta T}{M_{z f j} c_{z f j}} \\
-\frac{K D_{z f}^{n}}{C_{p}} \times\left(\frac{1}{\mu_{z f}}+H_{s m}-H_{z f}\right) \frac{D_{s m}}{V_{z f} \rho_{z f}}, \\
-\frac{\rho_{z f}^{2}+\mu_{z f} L \varepsilon D_{z f}^{2}}{2 \rho_{z f} V_{z f} \mu_{z f} L \varepsilon}+\frac{\rho_{z f}^{2}+\mu_{z f} L \varepsilon D_{z f}^{2}}{2 V_{z f} \mu_{z f} D_{z f} L \varepsilon \rho_{z f}} D_{s m} .
\end{gathered}
$$

The affine nonlinear system [36] can be defined as

$$
\begin{gathered}
\dot{x}=f(x)+\sum_{i=1}^{m} g_{i}(x) u_{i}, \\
y=h(x),
\end{gathered}
$$

where the state vector $x$ about (9) is $x=\left[x_{1}, x_{2}, x_{3}, x_{4}, x_{5}\right]^{T}=$ $\left[H_{f l}, Q_{f l}, H_{z f}, Q_{z f f}, D_{z f}\right]^{T}$, the control vectors are $u_{1}=D_{s m}$ 
and $u_{2}=B$, and the vectors $f(x), g_{1}(x)$, and $g_{2}(x)$ can be written as

$$
\begin{aligned}
& f(x) \\
& =\left[\begin{array}{c}
\frac{D_{z f}\left(x_{3}-x_{1}\right)}{V_{f l} \rho_{f l}}-\frac{x_{2}}{V_{f l} \rho_{f l}} \\
\frac{\alpha A}{C_{p} V_{f l} \rho_{f l}} D_{z f}\left(x_{3}-x_{1}\right)-\left(\frac{\alpha A}{C_{p} V_{f l} \rho_{f l}}+\frac{\alpha A}{M_{f l j} c_{f l j}}\right) x_{2} \\
\frac{1}{V_{z f} \rho_{z f}}\left(x_{4}-\frac{D_{z f}}{\mu_{z f}}\right) \\
\frac{x_{5}-\mu_{z f} x_{4}}{C_{p} V_{z f} \rho_{z f} \mu_{z f}} K x_{5} \\
-\frac{\rho_{z f}^{2}+\mu_{z f} L \varepsilon x_{5}^{2}}{2 \rho_{z f} V_{z f} \mu_{z f} L \varepsilon}
\end{array}\right], \\
& g_{1}(x)=\left[\begin{array}{c}
0 \\
0 \\
\left(\frac{1}{\mu_{z f}}+H_{s m}-x_{3}\right) \frac{1}{V_{z f} \rho_{z f}} \\
-\frac{K x_{5}}{C_{p} V_{z f} \rho_{z f}}\left(\frac{1}{\mu_{z f}}+H_{s m}-x_{3}\right) \\
\frac{\rho_{z f}^{2}+\mu_{z f} L \varepsilon x_{5}^{2}}{2 V_{z f} \mu_{z f} x_{5} L \varepsilon \rho_{z f}}
\end{array}\right] \\
& g_{2}(x)=\left[\begin{array}{c}
0 \\
0 \\
0 \\
\frac{K x_{5}^{n}}{M_{z f j} c_{z f j}} \phi V_{c} \Delta T \\
0
\end{array}\right] .
\end{aligned}
$$

2.2. Exact Feedback Linearizing Controller Design. The nonlinear system is difficult to solve as the model from (9) includes five independent variables. To simplify the model of IPT, only the variables and equations which are related to IPT are chosen while others are ignored. The simplified model is expressed in the general form of affine nonlinear system (10). The chosen equations can be written as

$$
\begin{aligned}
\frac{d H_{z f}}{d \tau}= & \frac{1}{V_{z f} \rho_{z f}}\left(Q_{z f f}-\frac{D_{z f}}{\mu_{z f}}\right) \\
& +\left(\frac{1}{\mu_{z f}}+H_{s m}-H_{z f}\right) \frac{D_{s m}}{V_{z f} \rho_{z f}}, \\
\frac{d H_{f l}}{d \tau}= & \frac{D_{z f}\left(H_{z f}-H_{f l}\right)}{V_{f l} \rho_{f l}}-\frac{Q_{f l}}{V_{f l} \rho_{f l}} .
\end{aligned}
$$

Due to definition of (10), the state vector is $x=\left[x_{1}, x_{2}\right]^{T}=$ $\left[H_{z f}, H_{f l}\right]^{T}$, the output vector is $y=h(x)=H_{f l}=x_{2}$, the control vector is $u=D_{s m}$, and the vectors $f(x), g(x)$ are

$$
\begin{gathered}
f(x)=\left[\begin{array}{c}
\frac{1}{V_{z f} \rho_{z f}}\left(Q_{z f f}-\frac{D_{z f}}{\mu_{z f}}\right) \\
\frac{D_{z f}\left(x_{1}-x_{2}\right)}{V_{f l} \rho_{f l}}-\frac{Q_{f l}}{V_{f l} \rho_{f l}}
\end{array}\right], \\
g(x)=\left[\left(\frac{1}{\mu_{z f}}+H_{s m}-x_{1}\right) \frac{1}{V_{z f} \rho_{z f}}\right] .
\end{gathered}
$$

Therefore, the chosen model (12) could be considered as a single-input and single-output system. The controller based on exact feedback linearization can be designed through the following steps.

2.2.1. Calculation of Relative Degree and Coordinate Transformation. In order to obtain the relative degree, the LIE derivative should be calculated.

Firstly, the LIE derivative is figured out as

$$
\begin{gathered}
L_{g} L_{f}^{0} h(x)=\frac{\partial h(x)}{\partial x} g(x)=0, \\
L_{f} h(x)=\frac{\partial h(x)}{\partial x} f(x)=\frac{D_{z f}\left(x_{1}-x_{2}\right)}{V_{f l} \rho_{f l}}-\frac{Q_{f l}}{V_{f l} \rho_{f l}}, \\
L_{g} L_{f} h(x)=\frac{\partial\left(L_{f} h(x)\right)}{\partial x} g(x)=\frac{D_{z f}}{V_{f l} \rho_{f l} V_{z f} \rho_{z f}} \\
\times\left(\frac{1}{\mu_{z f}}+H_{s m}-x_{1}\right), \\
L_{f}^{2} h(x)=\frac{\partial\left(L_{f} h(x)\right)}{\partial x} g(x)=\frac{D_{z f}\left(Q_{z f f}-\left(D_{z f} / u_{z f}\right)\right)}{V_{f l} \rho_{f l} V_{z f} \rho_{z f}} \\
-\frac{D_{z f}}{\left(V_{f l} \rho_{f l}\right)^{2}}\left[D_{z f}\left(x_{1}-x_{2}\right)-Q_{f l}\right] .
\end{gathered}
$$

Assuming that $\left(1 / \mu_{z f}\right)+H_{s m}-x_{1} \neq 0$ from (15) is satisfied, therefore the relation degree is $r=n=2$.

Secondly the coordinate transformation $z=\Phi(x)$ can be written as

$$
\Phi:\left\{\begin{array}{l}
z_{1}=x_{2}-R_{s}, \\
z_{2}=L_{f} h(x)=\frac{1}{V_{f l} \rho_{f l}}\left[D_{z f}\left(x_{1}-x_{2}\right)-Q_{f l}\right]
\end{array}\right.
$$

where $R_{s}$ is the referenced steam enthalpy at the outlet of the separator and also named as the referenced intermediate point enthalpy in this paper $\left(R_{s}=H_{f l}=2666.89 \mathrm{~kJ} / \mathrm{kg}\right)$. 
Finally, a new linear system after coordinate transformation and exact feedback linearization is derived as

$$
\begin{aligned}
& \dot{z}_{1}=z_{2}, \\
& \dot{z}_{2}=v=L_{f}^{2} h(x)+L_{g} L_{f} h(x) u,
\end{aligned}
$$

where $v$ is named as the optimal control vector of the linear system. The linear system is $\dot{z}=A z+B v$, which is a completely controllable Brunovsky linear system.

2.2.2. Design of Control Law. Using the optimal control law [37], $v$ can be written as

$$
\begin{aligned}
v= & -K z=-\left(k_{1} z_{1}+k_{2} z_{2}\right)=-k_{1}\left(x_{2}-R_{s}\right) \\
& -\frac{k_{2}}{V_{f l} \rho_{f l}}\left[D_{z f}\left(x_{1}-x_{2}\right)-Q_{f l}\right],
\end{aligned}
$$

where $K=R^{-1} B^{T} P$. Assuming that $R=1, P$ is the solution of the following Riccati equation:

$$
A^{T} P+P A-P B B^{T} P+Q=0,
$$

where the Brunovsky standard coefficient matrices $A$ and $B$ are

$$
A=\left[\begin{array}{ll}
0 & 1 \\
0 & 0
\end{array}\right], \quad B=\left[\begin{array}{l}
0 \\
1
\end{array}\right] .
$$

$Q$ is a positive definite or semidefinite symmetric matrix. Assuming that $Q=\left[\begin{array}{ll}1 & 0 \\ 0 & 0\end{array}\right]$, the solution of (19) is derived as

$$
P=\left[\begin{array}{cc}
\sqrt{2} & 1 \\
1 & \sqrt{2}
\end{array}\right], \quad K=\left[\begin{array}{ll}
k_{1} & k_{2}
\end{array}\right]=\left[\begin{array}{ll}
1 & \sqrt{2}
\end{array}\right] .
$$

Therefore, the optimal control vector $v$ from (18) can be written as

$$
v=-\left(x_{2}-R_{s}\right)-\frac{1.414}{V_{f l} \rho_{f l}}\left[D_{z f}\left(x_{1}-x_{2}\right)-Q_{f l}\right] .
$$

As the relationship between linearity and nonlinearity is $u=\left(-L_{f}^{2} h(x)+v\right) / L_{g} L_{f} h(x)$, the exact feedback linearizing control law can be obtained as

$$
\begin{aligned}
u=( & -\frac{D_{z f}\left(Q_{z f f}-\left(D_{z f} / u_{z f}\right)\right)}{V_{f l} \rho_{f l} V_{z f} \rho_{z f}} \\
& \left.+\frac{D_{z f}}{\left(V_{f l} \rho_{f l}\right)^{2}}\left[D_{z f}\left(x_{1}-x_{2}\right)-Q_{f l}\right]\right) \\
& \times\left(\frac{D_{z f}}{V_{f l} \rho_{f l} V_{z f} \rho_{z f}}\left(\frac{1}{\mu_{z f}}+H_{s m}-x_{1}\right)\right)^{-1} \\
& +\left(-\left(x_{2}-R_{s}\right)-1.414 \frac{1}{V_{f l} \rho_{f l}}\left[D_{z f}\left(x_{1}-x_{2}\right)-Q_{f l}\right]\right) \\
& \times\left(\frac{D_{z f}}{V_{f l} \rho_{f l} V_{z f} \rho_{z f}}\left(\frac{1}{\mu_{z f}}+H_{s m}-x_{1}\right)\right)^{-1} .
\end{aligned}
$$

\section{Simulation on Control of IPT via Affine Nonlinear System}

To verify the validation of the law (23) for supercritical units, the stability analysis and simulations of the proposed algorithms are necessary and essential.

3.1. System Stability Analysis. The enthalpy formula is difined as

$$
\begin{aligned}
H= & 2022.7+1.6657 T+2.96 \times 10^{-4} T^{2}-1.356 \times 10^{9} T^{-2.81} p \\
& -6.1621 \times 10^{24} T^{-8.939} p^{2} .
\end{aligned}
$$

The enthalpy can be obtained by using (24). Here is the list of the parameters for a $600 \mathrm{MW}$ supercritical unit (boiler type: SG1913/25.40-MXXX). $T_{f l}=683.15 \mathrm{~K}, P_{f l}=27.8 \mathrm{Mpa}$, $H_{f l}=2666.8898 \mathrm{~kJ} / \mathrm{kg}, \rho_{z f}=167 \mathrm{~kg} / \mathrm{m}^{3}, \rho_{f l}=100 \mathrm{~kg} / \mathrm{m}^{3}$, $\mu_{z f}=13.23\left(\mathrm{~kg} / \mathrm{m}^{3}\right) / \mathrm{Mpa}, Q_{z f f}=417 \mathrm{~kJ} / \mathrm{s}, Q_{f l}=1200 \mathrm{~kJ} / \mathrm{s}$, $D_{z f}=486 \mathrm{~kg} / \mathrm{s}, V_{z f}=46.23 \mathrm{~m}^{3}$, and $V_{f l}=6.29 \mathrm{~m}^{3}$.

With these parameters at full load, the equations are obtained as

$$
\begin{aligned}
\dot{x}_{1}=\frac{417-\left(D_{z f} / 13.23\right)}{7720.41}+\left(1863.37-x_{1}\right) \frac{u}{7720.41}, \\
\dot{x}_{2}=\frac{D_{z f}\left(x_{1}-x_{2}\right)}{629}-1.91, \\
u=\left(\frac{-D_{z f}\left(417-\left(D_{z f} / 13.23\right)\right)}{4856137.89}+\frac{D_{z f}}{395641}\right. \\
\left.\times\left[D_{z f}\left(x_{1}-x_{2}\right)-1200\right]\right)
\end{aligned}
$$

$$
\begin{aligned}
& \times\left(\frac{D_{z f}}{4856137.89}\left(1863.37-x_{1}\right)\right)^{-1} \\
& +\left(-\left(x_{2}-R_{s}\right)-\frac{1.414 *\left[D_{z f}\left(x_{1}-x_{2}\right)-1200\right]}{629}\right) \\
& \times\left(\frac{D_{z f}}{4856137.89}\left(1863.37-x_{1}\right)\right)^{-1} .
\end{aligned}
$$

The Lyapunov Law is used to analyze the stability of the systems (25) and (26). The model (25) can be simplified as

$$
\begin{aligned}
\dot{x}_{1}= & \left(0.0016 D_{z f}-1.414\right)\left(x_{1}-x_{2}\right)-\frac{629 x_{2}}{D_{z f}} \\
& -1.916+\frac{629 R_{s}}{D_{z f}}+\frac{1696.8}{D_{z f}}, \\
\dot{x}_{2}= & \frac{D_{z f}\left(x_{1}-x_{2}\right)}{629}-1.91 .
\end{aligned}
$$




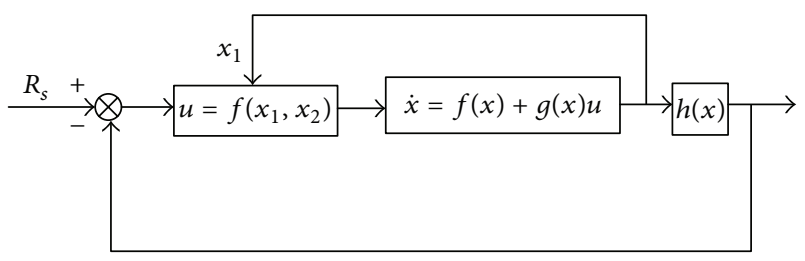

FIGURE 1: Structure diagram of affine nonlinear system.

Assuming that $T=-1.916+\left(629 R_{s}+1696.8\right) / D_{z f}$ and $(27)$ equals $0, x_{1}, x_{2}$ are derived as

$$
\begin{aligned}
& x_{1}=\frac{1195}{D_{z f}}+1.91 \times\left(0.0016 D_{z f}-1.414\right)+\frac{T D_{z f}}{629}, \\
& x_{2}=1.91 \times\left(0.0016 D_{z f}-1.414\right)+\frac{T D_{z f}}{629} .
\end{aligned}
$$

With the assumptions $\bar{x}_{1}=x_{1}-\left[\left(1195 / D_{z f}\right)+1.91 \times\right.$ $\left(0.0016 D_{z f}-1.414\right)+\left(T D_{z f} / 629\right), \bar{x}_{2}=x_{2}-[1.91 \times$ $\left.\left(0.0016 D_{z f}-1.414\right)+\left(T D_{z f} / 629\right)\right]$, the vector after derivative is obtained as

$$
\begin{aligned}
& \dot{\bar{x}}_{1}=\left(0.0016 D_{z f}-1.414\right)\left(\bar{x}_{1}-\bar{x}_{2}\right)-\frac{629}{D_{z f}} \bar{x}_{2}, \\
& \dot{\bar{x}}_{2}=\frac{D_{z f}\left(\bar{x}_{1}-\bar{x}_{2}\right)}{629} .
\end{aligned}
$$

Therefore, the coefficient matrix can be written as

$$
A=\left[\begin{array}{cc}
0.0016 D_{z f}-1.414 & -0.0016 D_{z f}+1.414-\frac{629}{D_{z f}} \\
\frac{D_{z f}}{629} & -\frac{D_{z f}}{629}
\end{array}\right] .
$$

At $100 \%$ load, $D_{z f}$ is $D_{z f}=486 \mathrm{~kg} / \mathrm{s}$. The eigenvalues after introducing $D_{z f}$ into (30) are $\lambda_{1}=-0.7047+0.7098 i$, $\lambda_{2}=-0.7047-0.7098 i$. According to the Lyapunov Law [38], if all eigenvalues of matrix $A$ have negative real parts, the system (25) is asymptotically stable under condition of (28). Therefore the system (25) is asymptotically stable at $100 \%$ load. The load is varied from $100 \%$ to $30 \%$ while keeping other parameters constant. The coefficient matrix eigenvalues at different loads are obtained and presented in Table 1.

From Table 1, it is shown that all coefficient matrix eigenvalues have negative real parts. Therefore, the nonlinear system is asymptotically stable at different loads.

3.2. Simulation with Disturbance of Feed-Water Flow. In order to reflect the real dynamic of the practical system, the feedwater flow disturbance is considered in the simulation. The structure diagram of affine nonlinear system is presented in Figure 1.

The model in Figure 1 is from (25), and the controller output is from (26). At $100 \%$ load, parameters $R_{s}$ and $D_{z f}$ are introduced into the system. The performance without the feed-water flow disturbance is presented in Figure 2.

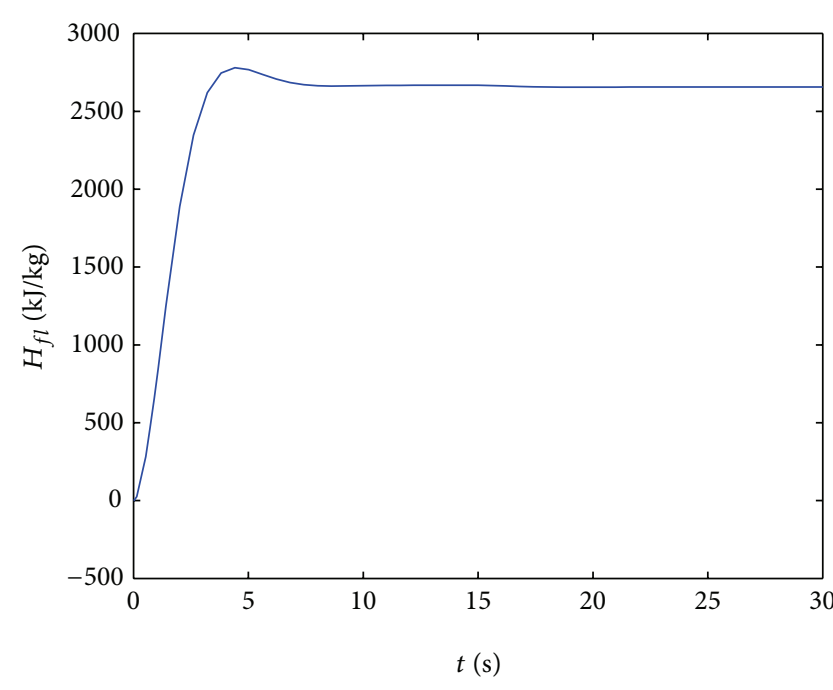

FIGURE 2: Performance of affine nonlinear system on IPT at $100 \%$ load.

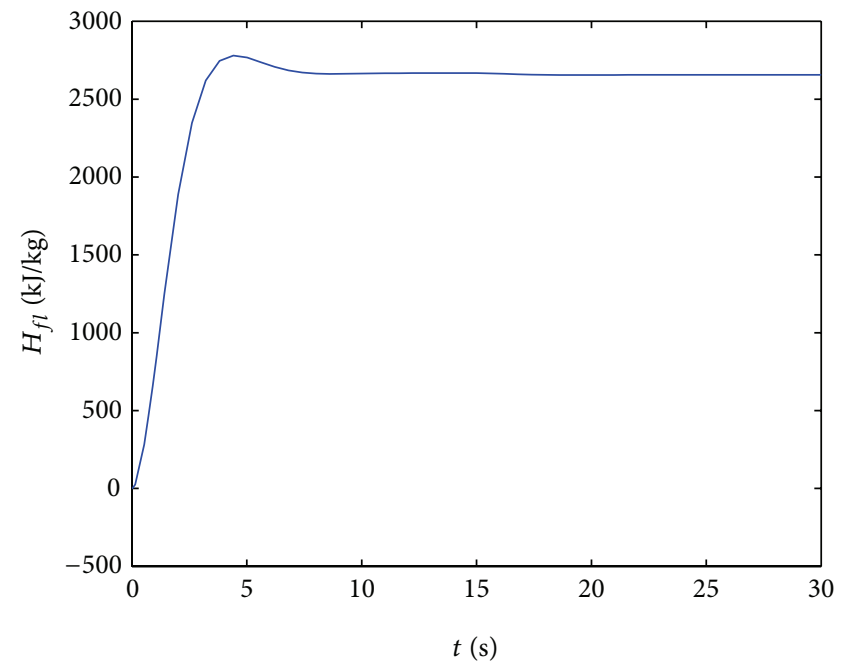

FIGURE 3: Performance with the feed-water flow disturbance at $100 \%$ load.

In Figure 2, at $100 \%$ load, the system peaks at $2765 \mathrm{~kJ} / \mathrm{kg}$ which means the overshoot is $3.7 \%$, the regulation time is $8 \mathrm{~s}$, and the steady-state output is $2667.4 \mathrm{~kJ} / \mathrm{kg}$. Then the noise signal is considered as the feed-water flow disturbance and injected into the controller output $u$. The system response is presented in Figure 3.

As shown in Figure 3, sudden increase of the feed-water flow can lead to the decrease of the intermediate point enthalpy. The result that the enthalpy of IPT recovers rapidly after disturbance means the performances match practical operation of the $600 \mathrm{MW}$ supercritical unit. Therefore, it is concluded that the model of affine nonlinear system on IPT in this paper is valid and reasonable.

3.3. Results at Different Loads. To study the affine nonlinear system further, more simulations have been conducted on 


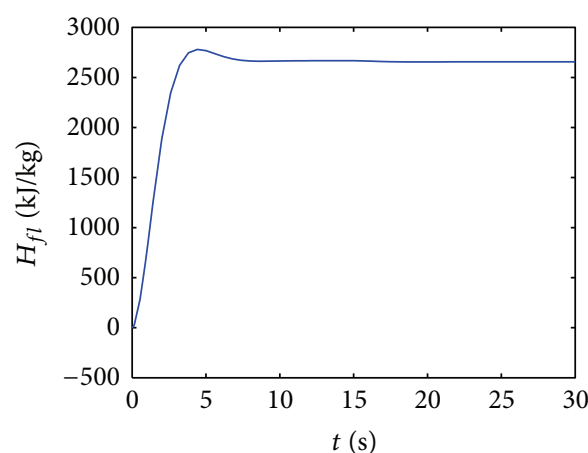

(a) $100 \%$

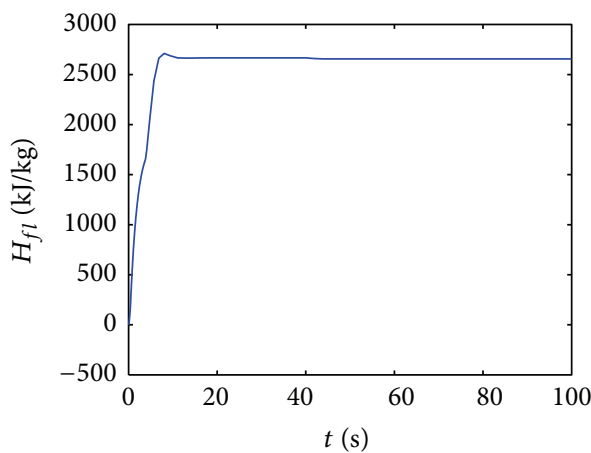

(c) $80 \%$

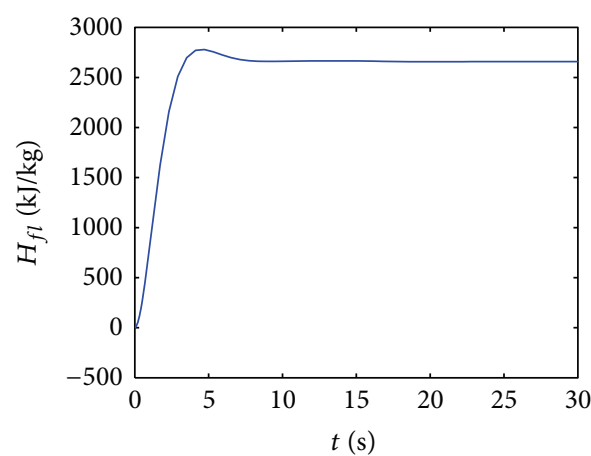

(e) $60 \%$

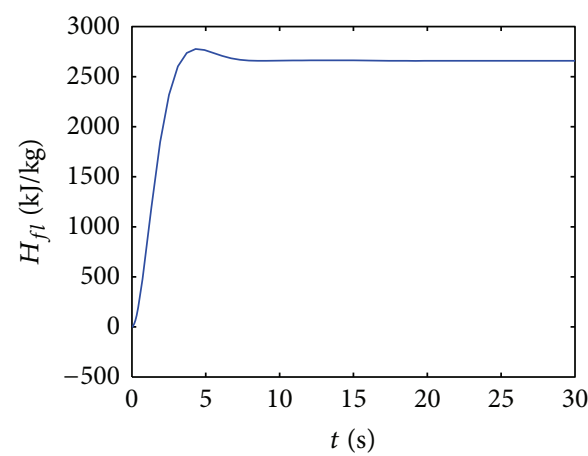

(g) $40 \%$

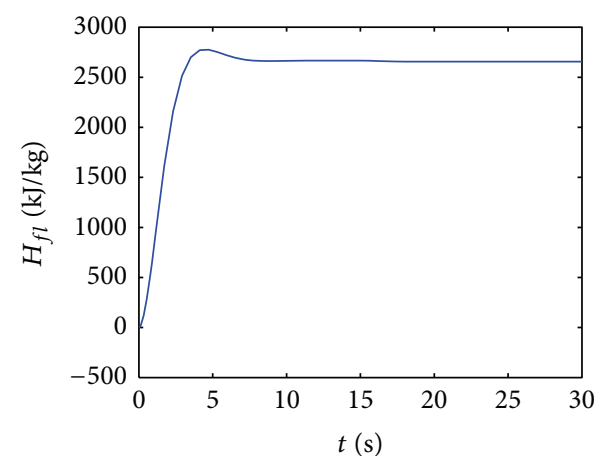

(b) $90 \%$

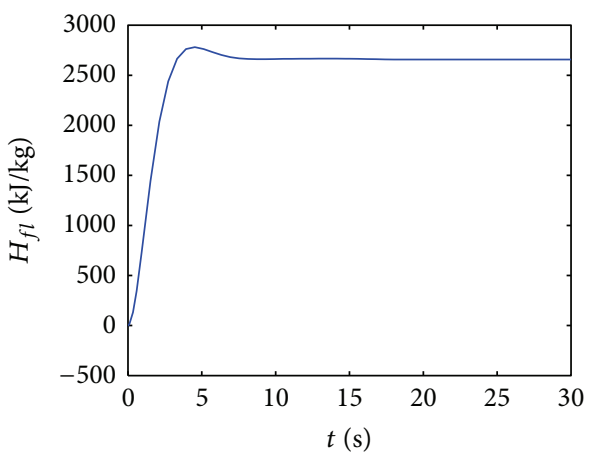

(d) $70 \%$

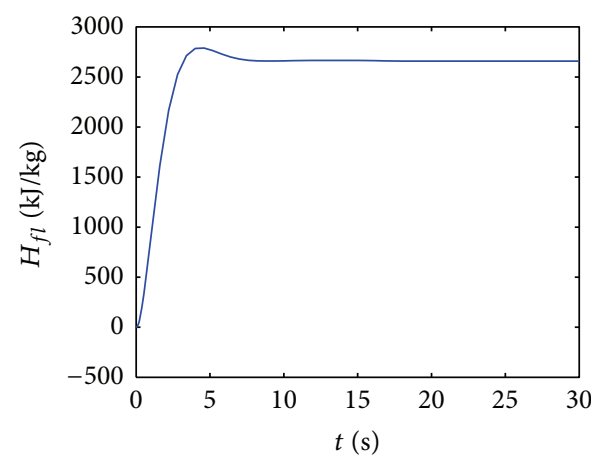

(f) $50 \%$

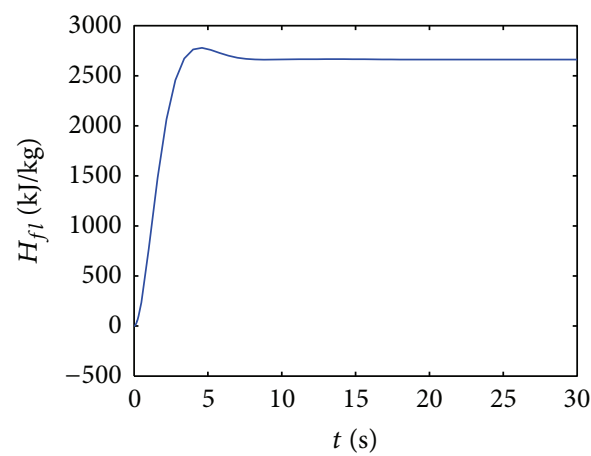

(h) $30 \%$

FIGURE 4: Response of affine nonlinear system at different loads. 
TABLE 1: Coefficient matrix eigenvalues at different loads.

\begin{tabular}{lccr}
\hline Load proportion & Load $D_{z f}(\mathrm{~kg} / \mathrm{s})$ & eigenvalue $\lambda_{1}$ & eigenvalue $\lambda_{2}$ \\
\hline $100 \%$ & 486 & $-0.7047+0.7098 i$ & $-0.7047-0.7098 i$ \\
$90 \%$ & 437.4 & $-0.7176+0.6961 i$ & $-0.7176-0.6961 i$ \\
$80 \%$ & 388.8 & $-0.7180+0.6959 i$ & $-0.7180-0.6959 i$ \\
$70 \%$ & 340.2 & $-0.7053+0.7091 i$ & $-0.7053-0.7091 i$ \\
$60 \%$ & 291.6 & $-0.7057+0.7091 i$ & $-0.7057-0.7091 i$ \\
$50 \%$ & 243 & $-0.7056+0.7081 i$ & $-0.7056-0.7081 i$ \\
$40 \%$ & 194.4 & $-0.7060+0.7081 i$ & $-0.7060-0.7081 i$ \\
$30 \%$ & 145.8 & $-0.7099+0.8783 i$ & $-0.7099-0.8783 i$ \\
\hline
\end{tabular}

TABLE 2: Simulation performances via affine nonlinear system.

\begin{tabular}{|c|c|c|c|c|c|}
\hline \multirow{2}{*}{ Load proportion } & \multicolumn{3}{|c|}{$R_{s}=2666.89 \mathrm{~kJ} / \mathrm{kg}$} & \multicolumn{2}{|c|}{ With feed-water flow } \\
\hline & $D_{z f}(\mathrm{~kg} / \mathrm{s})$ & $M_{D}(\%)$ & $t_{s 1}(\mathrm{~s})$ & $\sigma_{H}(\mathrm{~kJ} / \mathrm{kg})$ & $t_{s 2}(\mathrm{~s})$ \\
\hline $100 \%$ & 486 & 3.7 & 8 & -10.5 & 4 \\
\hline $90 \%$ & 437.4 & 4.1 & 9 & -10 & 4 \\
\hline $80 \%$ & 388.8 & 1.2 & 11 & -9.5 & 5 \\
\hline $70 \%$ & 340.2 & 4.2 & 9 & -9 & 4 \\
\hline $60 \%$ & 291.6 & 3.9 & 8 & -8 & 6 \\
\hline $50 \%$ & 243 & 4.3 & 9 & -7.5 & 6 \\
\hline $40 \%$ & 194.4 & 3.9 & 10 & -11 & 7 \\
\hline $30 \%$ & 145.8 & 4.2 & 8 & -4 & 5 \\
\hline
\end{tabular}

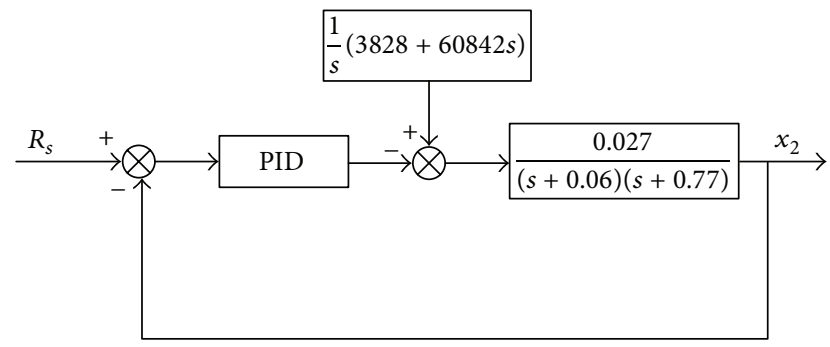

FIGURE 5: System structure diagram of PID control on IPT.

IPT for the $600 \mathrm{MW}$ supercritical unit at different loads (boiler type: SG1913/25.40-MXXX). While keeping other parameters constant, different loads leads to different $D_{z f}$, respectively, in Table 2 . Then simulations with the same feedwater flow disturbances have been conducted after substituting $D_{z f}$ into (25) and (26). The noise signal is considered as the feed-water flow disturbance and adopted into the controller output $u$ at $15 \mathrm{~s}$ (except $40 \mathrm{~s}$ at $80 \%$ load). The simulation performances at different loads are presented in Figure 4.

As shown in Figure 4(c), simulations at different loads are similar and tend to stability finally.

3.4. Results after Simulation. The results such as the overshoot $M_{D}$, the regulation time $t_{s}$, and the enthalpy difference $\sigma_{H}$ are recorded into Table 2 at different loads. $\left(t_{s 1}\right.$ : before increasing feed-water flow disturbance. $t_{s 2}$ : after increasing disturbance.)

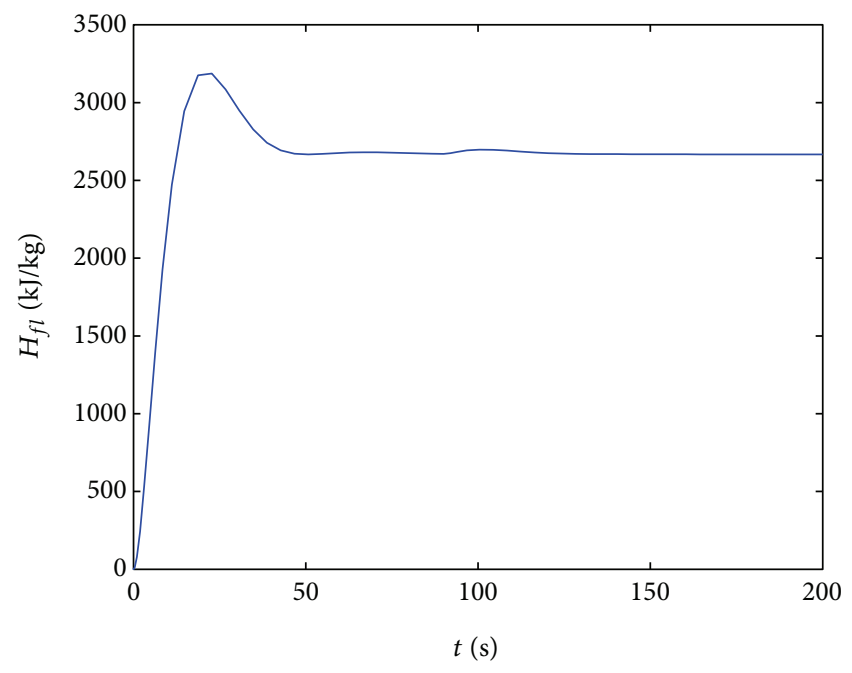

Figure 6: Response of PID control on IPT at 100\% load.

The results in Table 2 show that the model of affine nonlinear system is able to reduce the enthalpy with the increase of feed-water flow. Its results matche practical conditions and can recover stability rapidly.

\section{Contrast Study on IPT with PID Control}

\subsection{Simulation of PID Control}

4.1.1. Calculation of System Transfer Function. In engineer application, PID control is used widely. To compare it with 


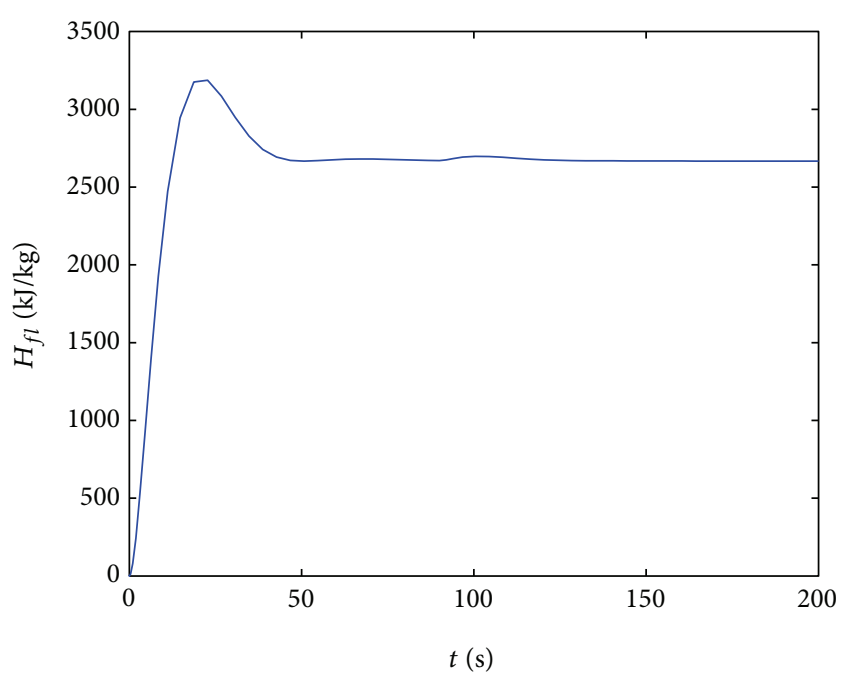

FIGURE 7: Performance of PID control with feed-water flow at $100 \%$ load.

the optimal control, the PID control is applied in this paper to control of IPT. As the model via affine nonlinear system is state equation which cannot be simulated with PID controller directly, it is essential that the system transfer function should be calculated by point approximation linearization. The first equation of (12) after derivation is obtained as

$$
\begin{aligned}
\frac{d\left(D_{s m}(t) H_{z f}(t)\right)}{d t} & =\frac{H_{z f}(t) d D_{s m}(t)}{d t}+\frac{D_{s m}(t) d H_{z f}(t)}{d t} \\
& \approx H_{z f}\left(t_{0}\right) \frac{d D_{s m}(t)}{d t}+D_{s m}\left(t_{0}\right) \frac{d H_{z f}(t)}{d t}
\end{aligned}
$$

Both sides of (31) after integrating at $t_{0}$ can be written as

$$
\begin{gathered}
D_{s m}(t) H_{z f}(t)=H_{z f}\left(t_{0}\right) D_{s m}(t)+H_{z f}(t) D_{s m}\left(t_{0}\right)+C \\
D_{s m}\left(t_{0}\right) H_{z f}\left(t_{0}\right)= \\
H_{z f}\left(t_{0}\right) D_{s m}\left(t_{0}\right) \\
+H_{z f}\left(t_{0}\right) D_{s m}\left(t_{0}\right)+C
\end{gathered}
$$

where $C=-D_{s m}\left(t_{0}\right) H_{z f}\left(t_{0}\right)$.

After substituting $C$ into (32), it can be derived as

$$
\begin{aligned}
D_{s m}(t) H_{z f}(t)= & H_{z f}\left(t_{0}\right) D_{s m}(t)+H_{z f}(t) D_{s m}\left(t_{0}\right) \\
& -D_{s m}\left(t_{0}\right) H_{z f}\left(t_{0}\right) .
\end{aligned}
$$

The first equation of (12) is simplified as

$$
\begin{aligned}
& \frac{d H_{z f}}{d t} \\
& =\frac{1}{V_{z f} \rho_{z f}}\left(Q_{z f f}-\frac{D_{z f}}{\mu_{z f}}\right)+\left(\frac{1}{\mu_{z f}}+H_{s m}\right) \frac{D_{s m}}{V_{z f} \rho_{z f}} \\
& \quad-\left(H_{z f}\left(t_{0}\right) D_{s m}(t)+H_{z f}(t) D_{s m}\left(t_{0}\right)\right. \\
& \left.\quad-D_{s m}\left(t_{0}\right) H_{z f}\left(t_{0}\right)\right) \times\left(V_{z f} \rho_{z f}\right)^{-1} .
\end{aligned}
$$

Assuming that $H_{z f}(t)$ and $D_{s m}(t)$ are variables which are only related to time $t,(34)$ after Laplace transform is

$$
\begin{aligned}
s H_{z f}(s)= & \frac{1}{s}\left(\frac{1}{V_{z f} \rho_{z f}}\left(Q_{z f f}-\frac{D_{z f}}{\mu_{z f}}\right)+\frac{D_{s m}\left(t_{0}\right) H_{z f}\left(t_{0}\right)}{V_{z f} \rho_{z f}}\right) \\
& +\left(\frac{\left(1 / \mu_{z f}\right)+H_{s m}-H_{z f}\left(t_{0}\right)}{V_{z f} \rho_{z f}}\right) D_{s m}(s) \\
& -\frac{H_{z f}(s) D_{s m}(s)}{V_{z f} \rho_{z f}} .
\end{aligned}
$$

The second equation of (12) after Laplace transform is expressed as

$$
s H_{f l}(s)=\frac{D_{z f}\left(H_{z f}(s)-H_{f l}(s)\right)}{V_{f l} \rho_{f l}}-\frac{Q_{f l}}{V_{f l} \rho_{f l} s} .
$$

The relationship between the intermediate point enthalpy and the feed-water flow is obtained as

$$
\begin{array}{r}
H_{f l}(s)=\frac{D_{z f} / V_{f l} \rho_{f l}}{\left(s+\left(D_{z f} / V_{f l} \rho_{f l}\right)\right)\left(s+\left(D_{s m}\left(t_{0}\right) / V_{z f} \rho_{z f}\right)\right)} \\
\times\left[\frac { 1 } { s } \left(\frac{1}{V_{z f} \rho_{z f}}\left(Q_{z f f}-\frac{D_{z f}}{\mu_{z f}}\right)\right.\right. \\
+\frac{D_{s m}\left(t_{0}\right)\left(H_{z f}\left(t_{0}\right)-\left(Q_{f l} / D_{z f}\right)\right)}{V_{z f} \rho_{z f}} \\
\left.\left.-\frac{\left.Q_{f l} s\right)}{\left.D_{z f}\right)}\right) D_{s m}(s)\right] .
\end{array}
$$

The enthalpy can be obtained by using (24). Here is the list of the parameters for a $600 \mathrm{MW}$ supercritical unit (boiler type: SG1913/25.40-MXXX). $T_{z f}=623.15 \mathrm{~K}, P_{z f}=28 \mathrm{Mpa}$, $H_{z f}=2132.07 \mathrm{~kJ} / \mathrm{kg}, T_{s m}=611.15 \mathrm{~K}, P_{s m}=29.83 \mathrm{Mpa}$, and $H_{s m}$ $=1863.29 \mathrm{~kJ} / \mathrm{kg}$.

The initial feed-water flow at the outlet of the coal economizer is $D_{s m}\left(t_{0}\right)=485.53 \mathrm{~kg} / \mathrm{s}$. Therefore, after $x_{2}(s)$ 


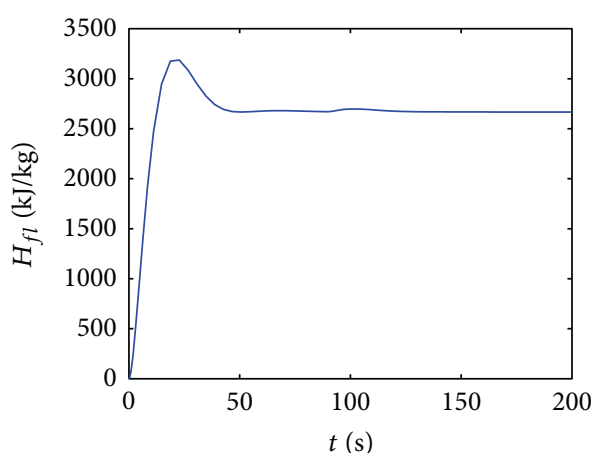

(a) $100 \%$

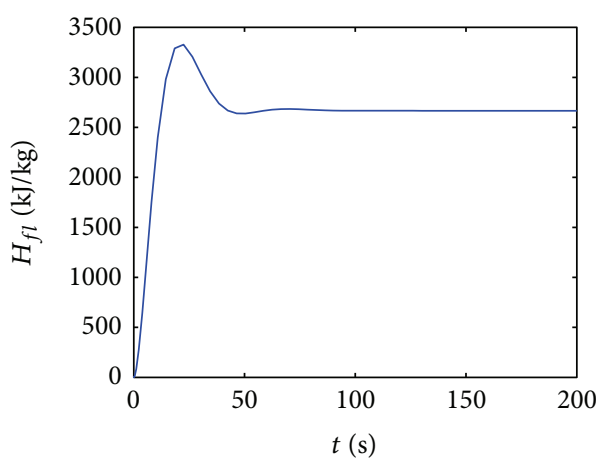

(c) $80 \%$

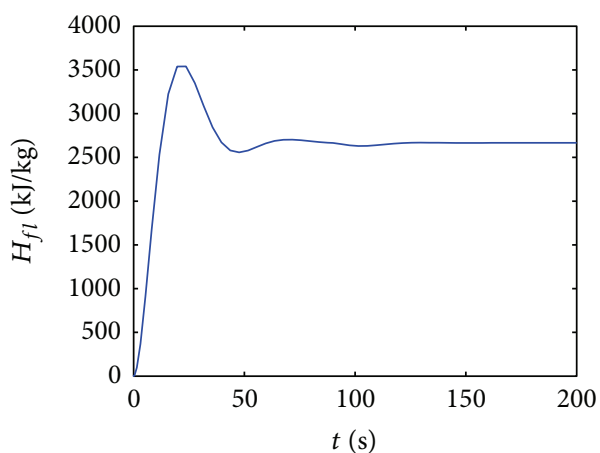

(e) $60 \%$

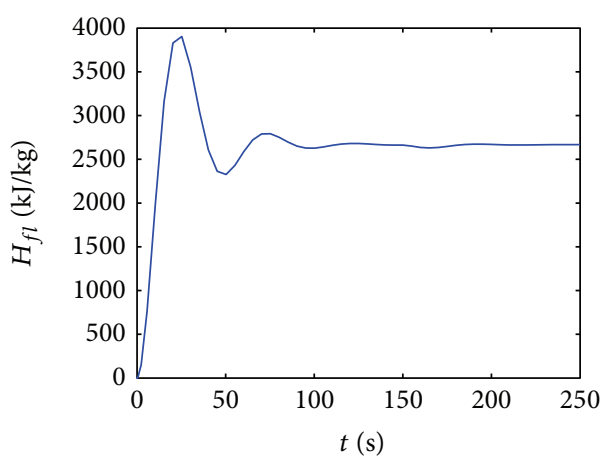

(g) $40 \%$

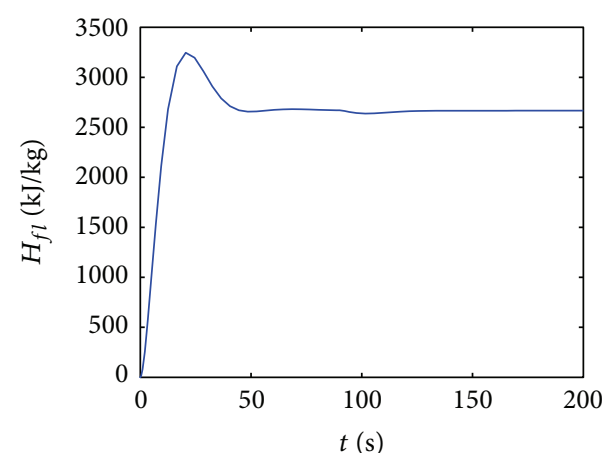

(b) $90 \%$

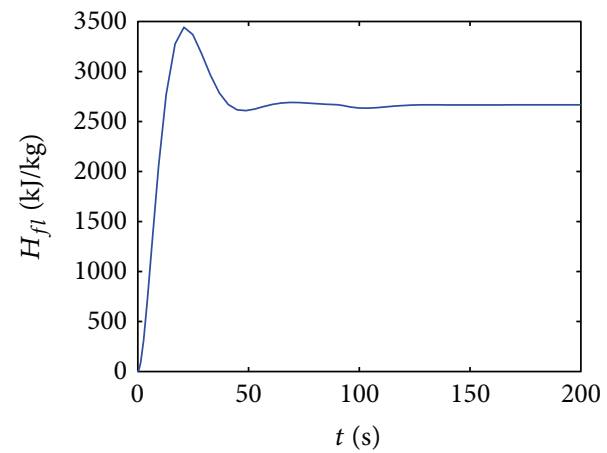

(d) $70 \%$

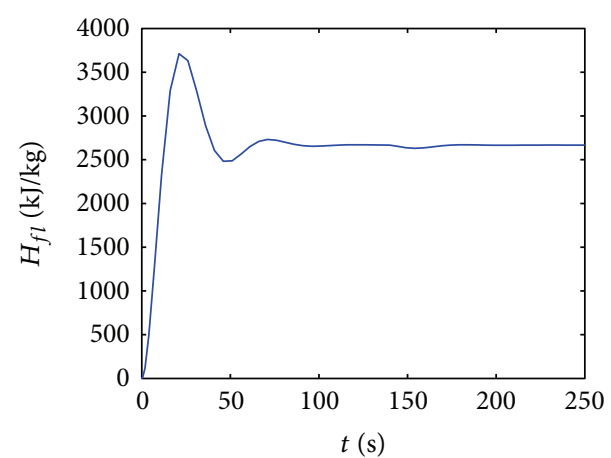

(f) $50 \%$

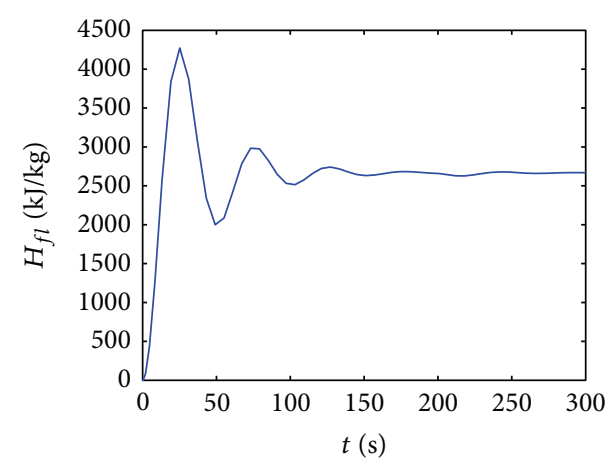

(h) $30 \%$

FIGURE 8: Response on system of PID control on at different loads. 
TABLE 3: Parameters $D_{z f}$ and $D_{s m}\left(t_{0}\right)$ at different loads.

\begin{tabular}{lcc}
\hline Load proportion & $D_{z f}(\mathrm{~kg} / \mathrm{s})$ & $D_{s m}\left(t_{0}\right)(\mathrm{kg} / \mathrm{s})$ \\
\hline $100 \%$ & 486 & 485.53 \\
$90 \%$ & 437.4 & 436.977 \\
$80 \%$ & 388.8 & 388.42 \\
$70 \%$ & 340.2 & 339.871 \\
$60 \%$ & 291.6 & 291.318 \\
$50 \%$ & 243 & 242.765 \\
$40 \%$ & 194.4 & 194.212 \\
$30 \%$ & 145.8 & 145.659
\end{tabular}

replacing $H_{f l}(s)$ and $u(s)$ replacing $D_{s m}(s)$, (37) at full load is simplified as

$$
\begin{aligned}
x_{2}(s)= & \frac{0.77}{(s+0.06)(s+0.77)} \\
& \times\left[\frac{103.16+1639.7 s}{0.77 s}-0.035 u(s)\right],
\end{aligned}
$$

where $(103.16+1639.7 s) /(0.77 s)$ is considered as disturbance.

Therefore, the system structure diagram after PID control of IPT is presented in Figure 5.

4.1.2. Simulation with Feed-Water Flow Disturbance. To verify the rationality of (38), the feed-water flow disturbance has been adopted into the system and the performance has been observed. At $100 \%$ load, PID simulation is conducted without the feed-water flow disturbance based on the system model in Figure 5. The simulation performance is presented in Figure 6.

As shown in Figure 6, the system peak at $100 \%$ load is $3186 \mathrm{~kJ} / \mathrm{kg}$ which means the overshoot is $19.4 \%$, the regulation time is $40 \mathrm{~s}$, and the steady-state output is $2666.98 \mathrm{~kJ} / \mathrm{kg}$. Then the noise signal is considered as the feed-water flow disturbance and adopted into the controller output $u$ at $90 \mathrm{~s}$. The simulation performance is presented in Figure 7.

As shown in Figure 7, sudden increase of feed-water flow could reduce the intermediate point enthalpy. The result that the enthalpy of IPT recovers rapidly after disturbance means the phenomenon matches practical operation of the $600 \mathrm{MW}$ supercritical unit. It is concluded that the model of the transfer function on IPT in this paper is valid and reasonable.

4.1.3. Simulation at Different Loads. The PID control of IPT for the $600 \mathrm{MW}$ supercritical unit has been simulated at different loads. For example, at $100 \%$ load, the simulation result with the feed-water disturbance is presented in Figure 7. While keeping other parameters constant, different loads lead to different parameters $D_{z f}$ and $D_{s m}\left(t_{0}\right)$, respectively, in Table 3 .

Then simulations are conducted after using the above parameters into (37). The noise signal is also considered as the feed-water flow disturbance and adopted into the controller output $u$ at $90 \mathrm{~s}$ (it is $140 \mathrm{~s}, 150 \mathrm{~s}$, and $200 \mathrm{~s}$ corresponding to $50 \%, 40 \%, 30 \%$ load). The performances at different loads are presented in Figure 8.

As shown in Figure 8, the results such as the overshoot $M_{D}$, the regulation time $t_{s}$, and the enthalpy difference $\sigma_{H}$ at different loads are recorded in Table 4 . $\left(t_{s 1}\right.$ : before increasing feed-water flow disturbance. $t_{s 2}$ : after increasing disturbance.)

\subsection{Stability Analysis Contrast PID with Control via Affine} Nonlinear System. Two methods include control based on exact feedback linearization via affine nonlinear system and PID control has been adopted to control the IPT of the $600 \mathrm{MW}$ supercritical unit. From Tables 2 and 4, the following conclusions can be made. (1) When the control via affine nonlinear system is adopted at different loads, the overshoot is smaller, the regulation time is shorter, and the enthalpy difference can be controlled into a smaller range. The new proposed method can meet the unit's requirements better comparing with the PID. (2) When PID control is adopted at different loads, the performances are less effective as the overshoot is bigger and the regulation time is longer.

\section{Conclusion}

In this paper, the affine nonlinear model of IPT for the supercritical boiler unit has been established. The optimal control method based on exact feedback linearization has been adopted into system with the feed-water flow disturbance at different loads. To verify the validation of the new method, PID control simulation is also conducted for the comparison. The control via affine nonlinear system based on exact feedback linearization can be more effectively on IPT. It is seen that the overshoot is smaller and the regulation time is shorter which shows it can meet the unit's requirements better at different loads. follows

The future plans for control of IPT have been proposed as

(1) More accurate models for the supercritical oncethrough boiler generation units should be established. Under practical operation, the models must be more complicated and more precise with high nonlinearity.

(2) More parameters changes should be considered. In this paper only the relationship between the feedwater flow and the IPT is focused on. More changing parameters should be studied in control of IPT in future.

(3) More control methods such as Robust Control [39] should be compared with the control via affine nonlinear system. In this paper only the PID control which is widely used on practical power plant control is compared with the new method. Future works will deal with IPT by considering the Robust Control. 
TABLE 4: Traditional PID control performance.

\begin{tabular}{|c|c|c|c|c|c|}
\hline \multirow{2}{*}{ Load proportion } & \multicolumn{3}{|c|}{$R_{s}=2666.89 \mathrm{~kJ} / \mathrm{kg}$} & \multicolumn{2}{|c|}{ With feed-water flow } \\
\hline & $D_{z f}(\mathrm{~kg} / \mathrm{s})$ & $M_{D}(\%)$ & $t_{s 1}(\mathrm{~s})$ & $\sigma_{H}(\mathrm{~kJ} / \mathrm{kg})$ & $t_{s 2}(\mathrm{~s})$ \\
\hline $100 \%$ & 486 & 19.4 & 40 & -29 & 20 \\
\hline $90 \%$ & 437.4 & 21.8 & 40 & -30 & 20 \\
\hline $80 \%$ & 388.8 & 25.3 & 40 & -31 & 20 \\
\hline $70 \%$ & 340.2 & 29 & 50 & -34 & 30 \\
\hline $60 \%$ & 291.6 & 32.8 & 55 & -37.4 & 30 \\
\hline $50 \%$ & 243 & 39.7 & 76 & -36.9 & 35 \\
\hline $40 \%$ & 194.4 & 46.3 & 84 & -39 & 40 \\
\hline $30 \%$ & 145.8 & 58.7 & 133 & -40.4 & 45 \\
\hline
\end{tabular}

\section{Conflict of Interests}

The authors declare that there is no conflict of interests regarding the publication of this paper.

\section{Acknowledgments}

The work was supported partly by the National Key Technology R\&D Program of China 2013BAA01B01, the National Natural Science Foundation of China under Grants nos. 61374064 and 61304152, and the China Postdoctoral Science Foundation Funded Project 2012M511258 and 2013T60738.

\section{References}

[1] T. Inoue, H. Taniguchi, Y. I. T. Inoue, and H. Taniguchi, "A model of fossil fueled plant with once-through boiler for power system frequency simulation studies," IEEE Transactions on Power Systems, vol. 15, no. 4, pp. 1322-1328, 2000.

[2] C. P. Bechlioulis and G. A. Rovithakis, "Prescribed performance adaptive control for multi-input multi-output affine in the control nonlinear systems," IEEE Transactions on Automatic Control, vol. 55, no. 5, pp. 1220-1226, 2010.

[3] N. Sharma, S. Bhasin, Q. Wang, and W. E. Dixon, "RISE-based adaptive control of a control affine uncertain nonlinear system with unknown state delays," IEEE Transactions on Automatic Control, vol. 57, no. 1, pp. 255-259, 2012.

[4] U. Moon and K. Y. Lee, "An adaptive dynamic matrix control with fuzzy-interpolated step-response model for a DRUM-type boiler-turbine system," IEEE Transactions on Energy Conversion, vol. 26, no. 2, pp. 393-401, 2011.

[5] R. Garduno-Ramirez and K. Y. Lee, "Wide range operation of a power unit via feedforward fuzzy control," IEEE Transactions on Energy Conversion, vol. 15, no. 4, pp. 421-426, 2000.

[6] X. Liu and C. W. Chan, "Neuro-fuzzy generalized predictive control of boiler steam temperature," IEEE Transactions on Energy Conversion, vol. 21, no. 4, pp. 900-908, 2006.

[7] A. Zdešar, O. Cerman, D. Dovžan, P. Hušek, and I. Škrjanc, "Fuzzy Control of a Helio-Crane-Comparison of Two Control Approaches," Journal of Intelligent and Robotic Systems: Theory and Applications, vol. 72, no. 3-4, pp. 497-515, 2013.

[8] X. J. Liu, X. B. Kong, G. L. Hou, and J. H. Wang, "Modeling of a $1000 \mathrm{MW}$ power plant ultra super-critical boiler system using fuzzy-neural network methods," Energy Conversion and Management, vol. 65, pp. 518-527, 2013.
[9] S. Lu and B. W. Hogg, "Dynamic nonlinear modelling of power plant by physical principles and neural networks," International Journal of Electrical Power and Energy System, vol. 22, no. 1, pp. 67-78, 2000.

[10] H. Zhang, Y. Luo, and D. Liu, "Neural-network-based nearoptimal control for a class of discrete-time affine nonlinear systems with control constraints," IEEE Transactions on Neural Networks, vol. 20, no. 9, pp. 1490-1503, 2009.

[11] X. Wu, J. Shen, Y. Li, and K. Y. Lee, "Data-driven modeling and predictive control for boiler-turbine unit," IEEE Transactions on Energy Conversion, vol. 28, no. 3, pp. 470-481, 2013.

[12] H. Peng, T. Ozaki, V. Haggan-Ozaki, and Y. Toyoda, "A nonlinear exponential ARX model-based multivariable generalized predictive control strategy for thermal power plants," IEEE Transactions on Control Systems Technology, vol. 10, no. 2, pp. 256-262, 2002.

[13] E. Gallestey, A. Stothert, M. Antoine, and S. Morton, "Model predictive control and the optimization of power plant load while considering lifetime consumption," IEEE Transactions on Power Systems, vol. 17, no. 1, pp. 186-191, 2002.

[14] Y. Wang and X. Yu, "New coordinated control design for thermal-power-generation units," IEEE Transactions on Industrial Electronics, vol. 57, no. 11, pp. 3848-3856, 2010.

[15] K. J. Åström and R. D. Bell, "Drum-boiler dynamics," Automatica, vol. 36, no. 3, pp. 363-378, 2000.

[16] S. Li, H. Liu, W. J. Cai, Y. C. Soh, and L. H. Xie, "A new coordinated control strategy for boiler-turbine system of coal-fired power plant," IEEE Transactions on Control Systems Technology, vol. 13, no. 6, pp. 943-954, 2005.

[17] I. Kocaarslan, E. Çam, and H. Tiryaki, "A fuzzy logic controller application for thermal power plants," Energy Conversion and Management, vol. 47, no. 4, pp. 442-458, 2006.

[18] I. Kocaarslan and E. Çam, "An adaptive control application in a large thermal combined power plant," Energy Conversion and Management, vol. 48, no. 1, pp. 174-183, 2007.

[19] U. Moon and K. Y. Lee, "A boiler-turbine system control using a fuzzy auto-regressive moving average (FARMA) model," IEEE Transactions on Energy Conversion, vol. 18, no. 1, pp. 142-148, 2003.

[20] U. Moon and K. Y. Lee, "Step-response model development for dynamic matrix control of a drum-type boiler-turbine system," IEEE Transactions on Energy Conversion, vol. 24, no. 2, pp. 423430, 2009.

[21] A. Sode-Yome, N. Mithulananthan, and K. Y. Lee, "A maximum loading margin method for static voltage stability in power systems," IEEE Transactions on Power Systems, vol. 21, no. 2, pp. 799-808, 2006. 
[22] K. Y. Lee, J. H. Van Sickel, J. A. Hoffman, W. Jung, and S. Kim, "Controller design for a large-scale ultrasupercritical once-through boiler power plant," IEEE Transactions on Energy Conversion, vol. 25, no. 4, pp. 1063-1070, 2010.

[23] Q. Yang and S. Jagannathan, "Reinforcement learning controller design for affine nonlinear discrete-time systems using online approximators," IEEE Transactions on Systems, Man, and Cybernetics B: Cybernetics, vol. 42, no. 2, pp. 377-390, 2012.

[24] M. Benosman and K.-. Lum, "Passive actuators' fault-tolerant control for affine nonlinear systems," IEEE Transactions on Control Systems Technology, vol. 18, no. 1, pp. 152-163, 2010.

[25] T. Ahmed-Ali, V. van Assche, J. Massieu, and P. Dorleans, "Continuous-discrete observer for state affine systems with sampled and delayed measurements," IEEE Transactions on Automatic Control, vol. 58, no. 4, pp. 1085-1091, 2013.

[26] Y. Yang and J. M. Lee, "Design of robust control Lyapunov function for non-linear affine systems with uncertainty," IET Control Theory \& Applications, vol. 6, no. 14, pp. 2248-2256, 2012.

[27] H. Deng, H. Li, and Y. Wu, "Feedback-linearization-based neural adaptive control for unknown nonaffine nonlinear discretetime systems," IEEE Transactions on Neural Networks, vol. 19, no. 9, pp. 1615-1625, 2008.

[28] F. Leonard, A. Martini, and G. Abba, "Robust nonlinear controls of model-scale helicopters under lateral and vertical wind gusts," IEEE Transactions on Control Systems Technology, vol. 20, no. 1, pp. 154-163, 2012.

[29] Q. Lu, S. Mei, W. Hu, F. F. Wu, Y. Ni, and T. Shen, "Nonlinear decentralized disturbance attenuation excitation control via new recursive design for multi-machine power systems," IEEE Transactions on Power Systems, vol. 16, no. 4, pp. 729-736, 2001.

[30] T.-L. Chien, C.-C. Chen, and C.-J. Huang, "Feedback linearization control and its application to MIMO cancer immunotherapy," IEEE Transactions on Control Systems Technology, vol. 18, no. 4, pp. 953-961, 2010.

[31] E. Semsar-Kazerooni, M. J. Yazdanpanah, and C. Lucas, "Nonlinear control and disturbance decoupling of HVAC systems using feedback linearization and backstepping with load estimation," IEEE Transactions on Control Systems Technology, vol. 16, no. 5, pp. 918-929, 2008.

[32] K. Fregene and D. Kennedy, "Stabilizing control of a highorder generator model by adaptive feedback linearization," IEEE Transactions on Energy Conversion, vol. 18, no. 1, pp. 149-156, 2003.

[33] A. Kusiak and Z. Song, "Clustering-based performance optimization of the boiler-turbine system," IEEE Transactions on Energy Conversion, vol. 23, no. 2, pp. 651-658, 2008.

[34] F. Casella, "Modeling, simulation, control, and optimization of a geothermal power plant," IEEE Transactions on Energy Conversion, vol. 19, no. 1, pp. 170-178, 2004.

[35] S. Barsali, A. de Marco, G. M. Giannuzzi, F. Mazzoldi, A. Possenti, and R. Zaottini, "Modeling combined cycle power plants for power system restoration studies," IEEE Transactions on Energy Conversion, vol. 27, no. 2, pp. 340-350, 2012.

[36] X. Liu and Z. Lin, "On normal forms of nonlinear systems affine in control," IEEE Transactions on Automatic Control, vol. 56, no. 2, pp. 239-253, 2011.

[37] N. Nakamura, H. Nakamura, and H. Nishitani, "Global inverse optimal control with guaranteed convergence rates of input affine nonlinear systems," IEEE Transactions on Automatic Control, vol. 56, no. 2, pp. 358-369, 2011.
[38] Y. Yang and J. M. Lee, "Design of robust control Lyapunov function for non-linear affine systems with uncertainty, IET Control Theory and Applications, vol. 6, no. 14, pp. 2248-2256, 2012.

[39] D. Dovžan and I. Škrjanc, "Control of mineral wool thickness using predictive functional control," Robotics and ComputerIntegrated Manufacturing, vol. 28, no. 3, pp. 344-350, 2012. 


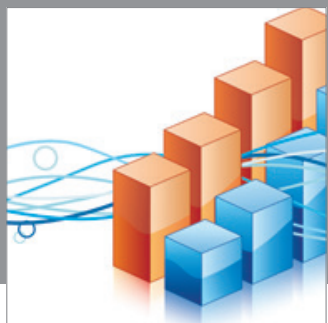

Advances in

Operations Research

mansans

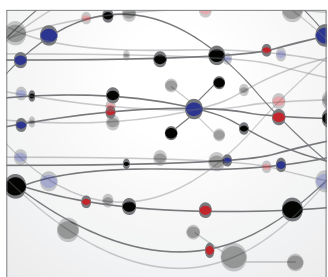

The Scientific World Journal
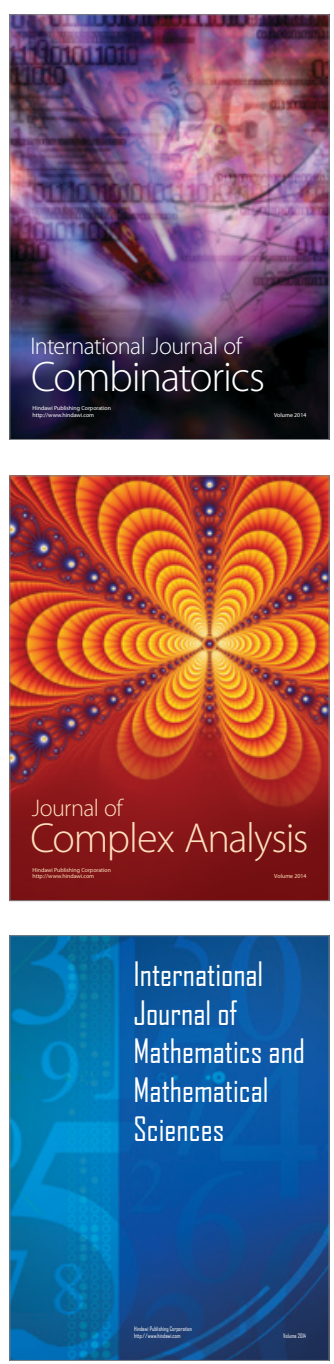
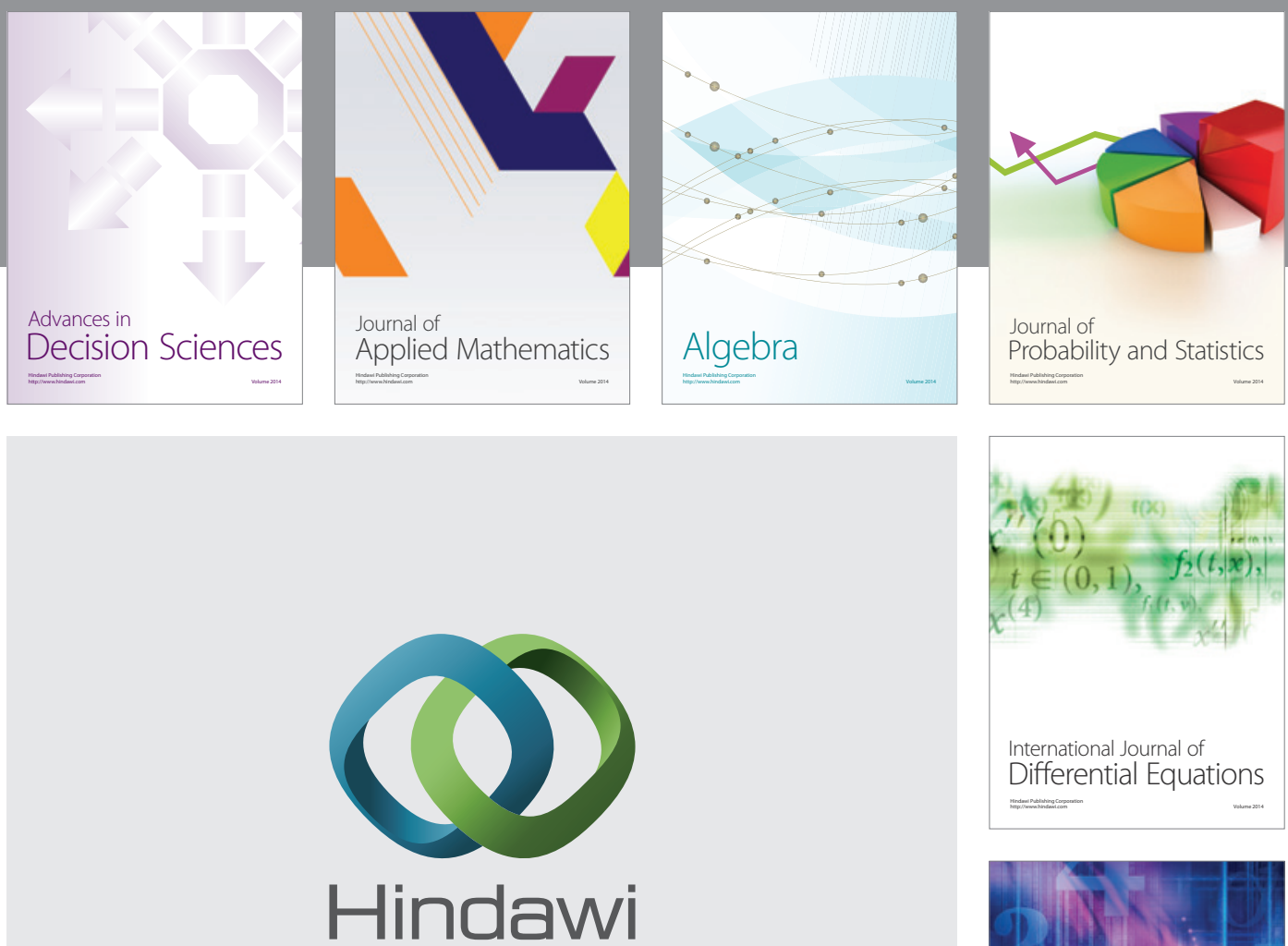

Submit your manuscripts at http://www.hindawi.com
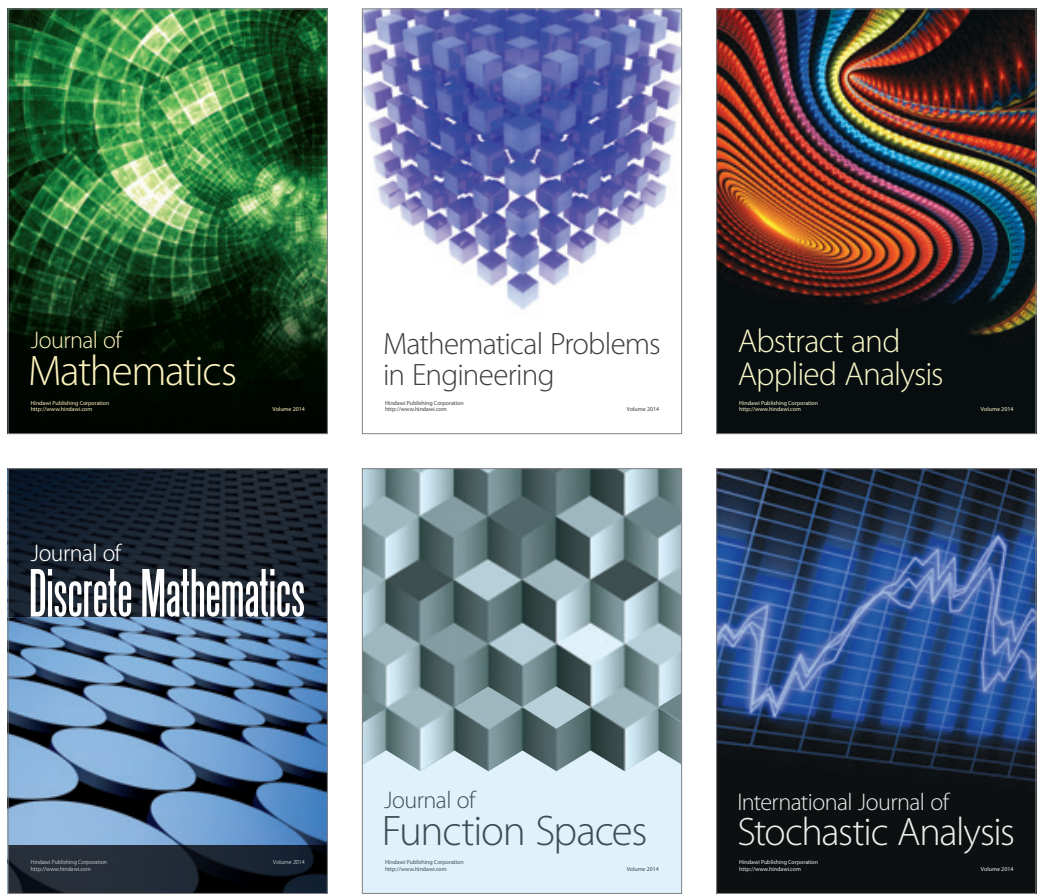

Journal of

Function Spaces

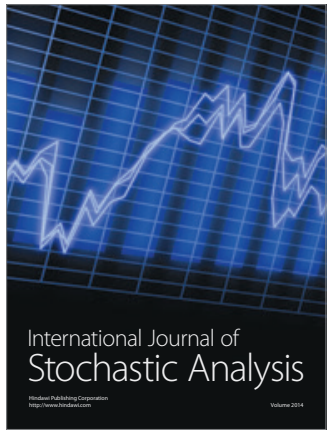

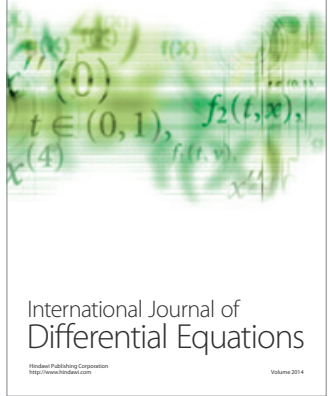
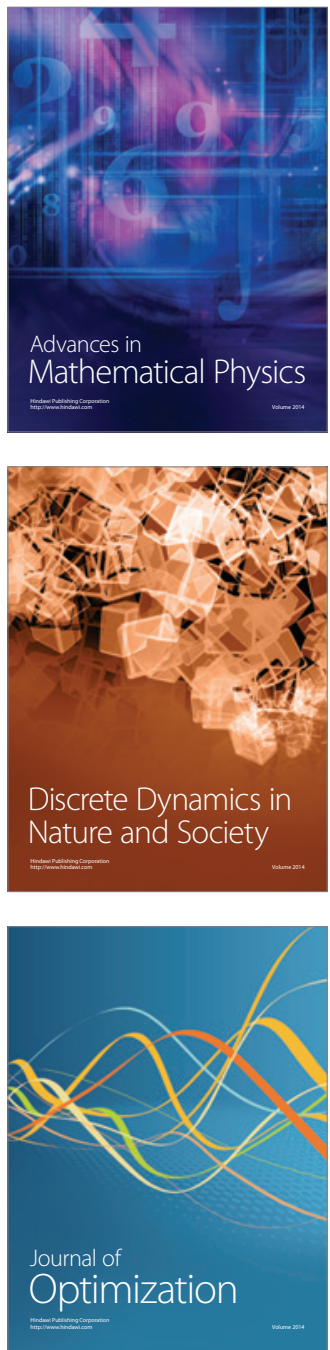